\title{
A Hypothesis: Linking Phase Separation to Meiotic Sex Chromosome Inactivation and Sex-Body Formation
}

\author{
Yiding Xu and Huanyu Qiao* \\ Department of Comparative Biosciences, University of Illinois at Urbana-Champaign, Urbana, IL, United States
}

OPEN ACCESS

Edited by:

Akira Shinohara

Osaka University, Japan

Reviewed by:

Jing Qu,

Institute of Zoology (CAS), China

Jesus Page,

Universidad Autómoma de Madrid

Spain

*Correspondence: Huanyu Qiao

hqiao@illinois.edu

Specialty section:

This article was submitted to

Cell Growth and Division,

a section of the journal

Frontiers in Cell and Developmental

Biology

Received: 28 February 2021

Accepted: 22 July 2021

Published: 16 August 2021

Citation:

Xu Y and Qiao H (2021) A

Hypothesis: Linking Phase Separation

to Meiotic Sex Chromosome

Inactivation and Sex-Body Formation.

Front. Cell Dev. Biol. 9:674203.

doi: 10.3389/fcell.2021.674203
During meiotic prophase $\mathrm{I}, \mathrm{X}$ and $\mathrm{Y}$ chromosomes in mammalian spermatocytes only stably pair at a small homologous region called the pseudoautosomal region (PAR). However, the rest of the sex chromosomes remain largely unsynapsed. The extensive asynapsis triggers transcriptional silencing - meiotic sex chromosome inactivation (MSCl). Along with $\mathrm{MSCl}$, a special nuclear territory, sex body or XY body, forms. In the early steps of MSCI, DNA damage response (DDR) factors, such as BRCA1, ATR, and $\gamma H 2 A X$, function as sensors and effectors of the silencing signals. Downstream canonical repressive histone modifications, including methylation, acetylation, ubiquitylation, and SUMOylation, are responsible for the transcriptional repression of the sex chromosomes. Nevertheless, mechanisms of the sex-body formation remain unclear. Liquid-liquid phase separation (LLPS) may drive the formation of several chromatin subcompartments, such as pericentric heterochromatin, nucleoli, inactive $X$ chromosomes. Although several proteins involved in phase separation are found in the sex bodies, when and whether these proteins exert functions in the sexbody formation and $\mathrm{MSCl}$ is still unknown. Here, we reviewed recent publications on the mechanisms of MSCl and LLPS, pointed out the potential link between LLPS and the formation of sex bodies, and discussed its implications for future research.

Keywords: meiosis, phase separation, sex body, DNA damage response, heterochromatin, meiotic sex chromosome inactivation

\section{INTRODUCTION}

Meiosis is a special cell division that generates four gametes containing haploid genome. After DNA replication, germline cells enter meiotic prophase I, a prolonged G2-like stage. During prophase I, homologous chromosomes pair up, synapse, and exchange genetic fragments via a process known as homologous recombination. In mammalian spermatocytes, sex chromosomes ( $\mathrm{X}$ and $\mathrm{Y})$ are transcriptionally silenced by a mechanism known as meiotic sex chromosome inactivation (MSCI). Unlike autosomes that fully synapse between homologs at pachytene stage, the X and Y chromosomes only stably pair at the pseudo-autosomal region (PAR). Concurrent with MSCI, the silenced $\mathrm{X}$ and $\mathrm{Y}$ chromosomes are condensed and remodeled to form a distinct chromatin domain called sex body or XY body. Although the mechanism of MSCI has been extensively studied, how the sex body is formed and how the sex chromosomes are silenced are still unclear.

Increasing evidence suggests that DNA damage response (DDR) factors play important roles in MSCI (Namekawa, 2012; Turner, 2015). Proteins that typically respond to DNA double-strand breaks (DSBs) were found in the initiation steps of MSCI (Ichijima et al., 2012). Mutations in DDR 
factors, such as BRCA1 (Turner et al., 2004), phosphorylated histone variant H2AX (Fernandez-capetillo et al., 2003), ATMand Rad3-related (ATR) kinase, ATR-activator TOPBP1 (Royo et al., 2013), and MDC1 (Ichijima et al., 2011), disrupt MSCI and sex-body formation, suggesting these factors play essential roles in silencing sex chromosomes. Recent publications on methyltransferase SETDB1 further linked the DDR with downstream histone modifications and transcriptional silencing (Hirota et al., 2018). However, many other linking proteins and histone modifications yet remain to be explored.

Recently developed high-throughput chromosome conformation capture (Hi-C) has become a powerful tool to investigate the genome-wide chromatin conformation and interaction during meiosis (Ke et al., 2017; Alavattam et al., 2019; Patel et al., 2019; Wang et al., 2019). Based on the observation that the inactive $\mathrm{X}$ chromosome is isolated and distinctly regulated, Alavattam et al. (2019) first pointed out that the XY body and post-meiotic sex chromatin might form physically separated liquid droplets. We generated a frequency difference map to compare the $\mathrm{Hi}-\mathrm{C}$ data of zygotene and pachytene chromosomes (sequencing data from Patel et al., 2019) and further confirmed that the sex body, as a separate territory, does not interact with other autosomes at pachytene stage (Figure 1; Page et al., 2012; Alavattam et al., 2019; Patel et al., 2019; Vara et al., 2019; Wang et al., 2019). Comparing to zygotene stage (Figure 1A), the interactions among autosomes are broadly reduced in pachytene stage, and contacts between the $\mathrm{X}$ chromosome and autosomes are completely lost (Figures 1B,C), indicating that sex chromosomes separate from autosomes at pachytene stage but not at zygotene stage. This is also described by Wang et al. (2019); they found that the X chromosome shows a unique chromatin configuration and largely loses topological association domains (TADs) and compartment features. These results are consistent with the observation of the distinct territory of sex chromosomes and the formation of the sex body (Figure 1D), which might largely abolish the interactions of sex chromosomes with autosomes.

While the factors involved in MSCI are well established, the mechanisms that physically separate sex chromosomes from autosomes have been an open question in the field. Wang et al. (2019) demonstrated there are more long-distance interactions within the $\mathrm{X}$ chromosome compared to autosomes, which may indicate $\mathrm{X}$ chromosomes are softer than stiff autosomes (Biggs et al., 2020). Unlike the rod-shaped autosomes, the territory of the $\mathrm{X}$ and $\mathrm{Y}$ chromosomes gradually becomes globe-shaped during sex-body formation. This unique sphere/egg-like shape of the sex body suggests surface tension at the liquid-liquid interface may minimize its surface area as what happens to oil droplets in water and phase-separated condensates in the nucleoplasm (Peng and Weber, 2019). Thus, we hypothesize that liquidliquid phase separation (LLPS) may participate in the physical separation of sex chromosomes from the other autosomes. LLPS is a process in which a homogenous fluid demixes into two distinct liquid phases, driving the formation of various cellular compartments. Similar to how water is separated from oil in an oil-water mixture, many membraneless organelles, such as the nucleolus, Cajal body, and nuclear stress body, are possibly separated from the surrounding matter by LLPS (Aumiller et al., 2014; Razin and Gavrilov, 2020; Lafontaine et al., 2021). In addition, it has been implicated that LLPS drives the formation of heterochromatin regions that are transcriptionally inactive and enriched for repetitive sequences (Strom et al., 2017). However, how the phase separation influences gene expression is still a field that must be researched further. The $\mathrm{X}$ chromosome inactivation (XCI) silences one of the $\mathrm{X}$ chromosomes in female somatic cells and is also potentially related to LLPS (Cerase et al., 2019). The similarities between sex bodies and other membraneless organelles, heterochromatin, and XCI raise the possibility that LLPS also promotes the formation of sex bodies.

Here, we described the features of the sex body and reviewed the molecular mechanisms of MSCI. We also discussed current models for LLPS and its biological functions. Moreover, we hypothesized that LLPS could be the mechanisms for sex-body formation by comparing it with other phase-separating cellular condensates. Finally, we described several in vivo and in vitro experimental approaches to study LLPS proteins in sex bodies.

\section{CHARACTERISTICS AND BEHAVIORS OF THE SEX BODY}

During meiotic prophase $\mathrm{I}$ in spermatocytes, the $\mathrm{X}$ and $\mathrm{Y}$ chromosomes undergo significant structural remodeling, compact into heterochromatin, and form the sex body. In the chromosomal spreads of early pachytene spermatocytes, the sex body is easily observed as a separated structure. During pachytene and diplotene stages, the sex body is deeply stained by Giemsa, possessing two joined and two separated ends of the $\mathrm{X}$ and $\mathrm{Y}$ chromosomes.

This large and darkly stained body was first observed in mammalian spermatocytes in the 1890s (Solari, 1974). Although it had been debated for a while whether a single X chromosome or both sex chromosomes are in this structure, later studies showed that both $\mathrm{X}$ and $\mathrm{Y}$ chromosomes are linked in this intranuclear body. Scientists first incorrectly named them "sex vesicles" because they assumed a surrounding membrane encloses sex chromosomes (Solari, 1969, 1974). However, after noticing that the "sex vesicle" appears not to be a membrane-bounded structure, researchers renamed it as the "sex body." Solari (1974) also reviewed early studies on sex-body histochemistry. Initial assumptions claimed that this "sex vesicle" is enriched with RNA (Kaplan et al., 1956), however, Solari and Tres (1967) disproved this hypothesis by showing that RNA is only limited to the nucleolus that is associated with the sex body.

Unlike autosomes, $\mathrm{X}$ and $\mathrm{Y}$ chromosomes only partially synapse at their ends in a region called the pseudoautosomal region (PAR) where sex chromosomes share sequence homology (700 kb in mouse) (Perry et al., 2001). In mouse early pachytene cells, the synaptonemal complex (SC) loads on to $72 \%$ of the length of the Y axis and 22\% of the X axis (Goetz et al., 1984). Furthermore, the chiasmata formed at the PAR is recognized at late pachytene stage (Burgoyne, 1982).

In summary, the sex body, a specialized and separated subnuclear structure, was identified and characterized in a set of 

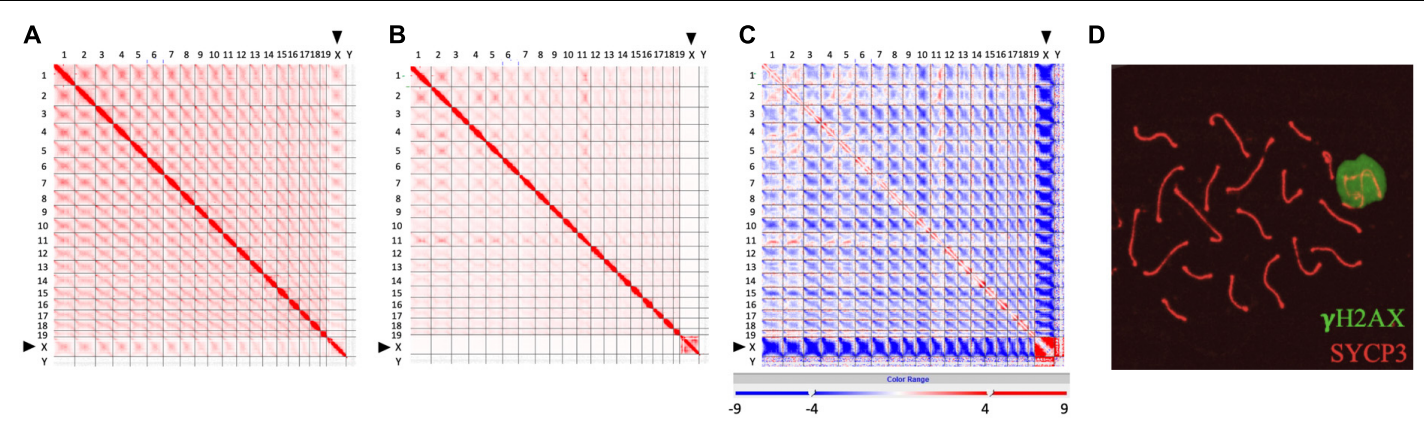

FIGURE 1 | Isolated sex chromosomes at pachytene stage. (A-C) Hi-C contact maps showing reduced interactions between X chromosome and autosomes at pachytene stage, compared to zygotene stage. (A) Genome-wide Hi-C contact map generated from zygotene spermatocytes (modified from Patel et al., 2019). (B) Genome-wide Hi-C contact map generated from pachytene spermatocytes (modified from Patel et al., 2019). (C) Frequency difference map showing differences of contact frequency between (A,B) (pachytene stage vs. zygotene stage) (data from Patel et al., 2019). In Hi-C contact maps (A,B), the intensity of each square represents the normalized number of contacts between a pair of chromosomes. Interactions between the X chromosome and other autosomes (1-19) at zygotene stage are more intensive than those at pachytene stage. In frequency difference map (C), the intensity of each square represents the contact frequency difference between maps (A,B). The intensive blue color shown between the X chromosome and autosomes indicates that contact frequency is significantly decreased in map (B) (pachytene stage), compared to map (A) (zygotene stage). (D) Images showing a sex body covered by $\gamma \mathrm{H} 2 \mathrm{AX}$ signal (green) in pachytene spermatocytes. Lateral elements of homologous chromosomes were stained by SYCP3 antibody (red).

early studies. Although the characteristics and behaviors of the sex body at different stages have been described, the molecular and biophysical processes underlying the sex-body formation within the nucleus are still unclear.

\section{MECHANISMS OF MSCI DURING MALE SPERMATOGENESIS}

In recent years, the indispensable functions of MSCI during sex-body formation attract scientists' attention. MSCI is a process that transcriptionally silences the $\mathrm{X}$ and $\mathrm{Y}$ chromosomes during meiotic prophase I of male spermatogenesis. After the zygotene-to-pachytene transition, any unsynapsed chromatin regions on autosomes are silenced by meiotic silencing of unsynapsed chromatin (MSUC) (Baarends et al., 2005; Turner et al., 2005). At pachytene stage, major portions of the $\mathrm{X}$ and $\mathrm{Y}$ chromosomes still keep unsynaped. Thus, the $\mathrm{X}$ and $\mathrm{Y}$ chromosomes compartmentalize to form a specialized nuclear domain and undergo transcriptional silencing (MSCI). Defects in MSCI cause misexpression of toxic sex-linked genes, such as Zfy 1/2 (Royo et al., 2010), that can eliminate the defective spermatocytes (Royo et al., 2015).

Mechanisms of MSUC, and specifically, MSCI, have been extensively studied (Figure 2). Two sets of proteins, sensors and effectors, sequentially act to generate the silencing of sex chromosomes. In response to asynapsis, sensors initiate the signaling of asynapsis, such as HORMAD1 (Daniel et al., 2011), HORMAD2 (Wojtasz et al., 2012), and BRCA1 (Turner et al., 2004). Some effectors first localize to the unsynapsed axes, then spread to their associated chromatin loops, and mediate MSCI (Turner, 2015). ATR-TOPBP1 complexes are loaded onto the unsynapsed axes of the sex chromosomes and phosphorylated H2AX at Ser139 (Royo et al., 2013). Then, ATR-TOPBP1 complex further spreads to the chromatin loops directed by MDC1 (Ichijima et al., 2011). With the spreading of ATR-TOPBP1 complex, $\mathrm{H} 2 \mathrm{AX}$ proteins along the chromatin loops are also phosphorylated by ATR, forming chromosome-wide $\gamma \mathrm{H} 2 \mathrm{AX}$ (Figure 2). $\gamma \mathrm{H} 2 \mathrm{AX}$ is essential for forming sex bodies and for inducing MSCI (Fernandez-capetillo et al., 2003). The sequential loading of MSCI-related proteins were summarized in Figures 2, 3 (Turner et al., 2004; Page et al., 2012; Turner, 2015).

MDC1 directly interacts with TOPBP1 and $\gamma \mathrm{H} 2 \mathrm{AX}$ during the amplification of phosphorylation signaling (Figure 2). In the absence of MDC1, ATR-TOPBP1, and $\gamma \mathrm{H} 2 \mathrm{AX}$ only restrict along the axes but not on the chromatin loops, indicating that the firststep axis localization of these DDR factors is MDC1-independent (Ichijima et al., 2011). Similarly, the failure of the chromosomewide spreading of DDR factors also occurs in H2ax-Y142A mouse model. This mouse model has a point mutation on the phosphorresidue Y142 of H2AX that disrupts the interaction of $\gamma \mathrm{H} 2 \mathrm{AX}$ and MDC1 (Abe et al., 2020).

Although the loading of DDR proteins at early steps of MSCI has been well studied, what links the DDR network to the transcriptional silencing is largely unknown. Histone modifications, such as acetylation and methylation (Khalil et al., 2004), are involved in silencing sex chromosomes. A methyltransferase SETDB1 is recruited by $\gamma \mathrm{H} 2 \mathrm{AX}$ and mediates a gene-silencing-related histone modification - the trimethylation of histone $\mathrm{H} 3$ lysine 9 (H3K9me3) (Hirota et al., 2018). Tripartite motif-containing 28 (TRIM28) or KAP1 possibly bridges DDR to SETDB1 and regulates transcription (Hirota et al., 2018). However, more complicated epigenetic reprogramming might be involved in MSCI. For instance, the canonical histone $\mathrm{H} 3.1$ and $\mathrm{H} 3.2$ are replaced by $\mathrm{H} 3.3$ on unsynapsed sex chromosomes at mid-pachytene stage (van der Heijden et al., 2007). This replacement is accompanied by the loss of most histone post-translational modifications (PTMs), including temporally loss of $\mathrm{H} 3 \mathrm{~K} 9 \mathrm{me} 3$ at pachytene stage (van der Heijden et al., 2007). This suggested there is a dramatic change in epigenetic modification and chromatin remodeling during both MSCI and MSUC. 


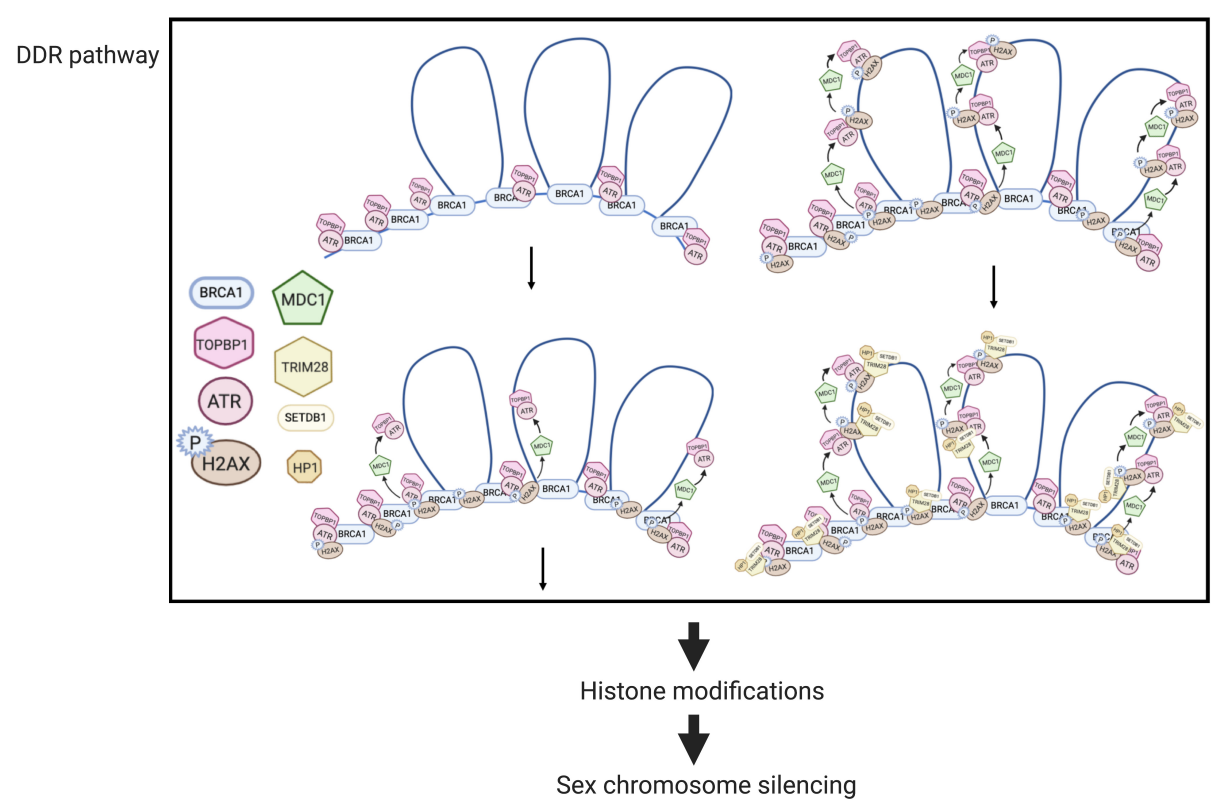

FIGURE 2 | MSCI mechanisms in mouse spermatocytes (modified from Ichijima et al., 2011). In DDR responses, BRCA1 first loads onto the unsynapsed chromosome axis, then recruits the ATR-TOPBP1 complex, which further spreads onto the chromatin loops facilitated by MDC1. H2AX is then phosphorylated by ATR, forming $\gamma$ - H2AX. Downstream of the DDR pathway, histone modifications mediate the transcriptional silencing of sex chromosomes.

\section{SEX-BODY FORMATION AND MSCI}

The precise time course of the sex-body formation and the silencing of sex chromosomes have been long discussed (Figure 3). At early pachytene stage, after the initial sexchromosome synapsis, MSCI-related proteins, such as SUMO1 (Small Ubiquitin Like Modifier 1), accumulate in the sex body (Rogers et al., 2004). At the same time, ubiquitin ligase UBR2 also localizes in the sex body and mediates histone $\mathrm{H} 2 \mathrm{~A}$ ubiquitination that is associated with transcriptional silencing of chromatin (Baarends et al., 2005). Page et al. (2012) demonstrated that silencing-related chromatin markers are present in the sex body before the transcriptional reactivation of autosomes. Thus, sex chromosomes may fail to reactivate at late zygotene stage rather than undergo inactivation at pachytene stage. Lau et al. (2020) also found transcriptional repression of the $\mathrm{X}$ chromosome starts before pachytene reactivation of autosomes by single-cell RNA-seq analysis. However, many other single-cell RNA-seq studies suggested that the initiation time of MSCI is pachytene stage (Chen et al., 2018; Green et al., 2018; Lukassen et al., 2018; Jung et al., 2019). The initiation-time difference may be caused by different clustering/staging approaches used in these RNA-seq studies.

As a separated, transcriptionally repressed chromatin region, the sex body harbors a range of specific proteins (Figure 3 ). DDR pathway proteins are found to be "sequestered" from the autosomes to the sex chromosome region at the initiation of MSCI (Abe et al., 2020). This "sequestration" effect could be explained by the high physicochemical affinity among these proteins (Handel, 2020). Besides those DDR factors, other proteins found in the sex body are also involved in heterochromatin formation. For instance, histone methyltransferase SUV39H2, a protein that modulates chromatin dynamics and usually distributes at the heterochromatin, accumulates to the sex-body region in pachytene spermatocytes (O'Carroll et al., 2000). Similarly, histone modification H3K9me3 plays an important role in meiotic heterochromatin assembly (Reuben and Lin, 2002; Hirota et al., 2018). H3K9me3 immunostaining signal increases in the sex-body region at early-mid pachytene transition, followed by temporal loss from mid/late-pachytene to late diplotene stage (van der Heijden et al., 2007; Page et al., 2012). Heterochromatin protein 1 (HP1), which binds to $\mathrm{H} 3 \mathrm{~K} 9 \mathrm{me} 3$, has been shown to be related to chromatin condensation and transcriptional regulation. Two isoforms of the HP1 proteins, HP1 $\beta$ and HP1 $\gamma$, decorate the entire sex body at late pachytene stage in human spermatocytes (MetzlerGuillemain et al., 2003), indicating their potential roles in condensing and silencing the sex chromosomes. However, more precise timing of HP1 loading should be explored, considering the complexity of histone modifications during MSCI. More interestingly, HP1-promoted phase separation has been proposed to facilitate the formation of chromatin sub-compartments (Erdel and Rippe, 2018) as well as transcriptional control (Hnisz et al., 2017).

Taken together, these studies provide evidence for potential close associations between MSCI and sex-body formation; however, the mechanisms underlying both processes need to be elucidated. Besides those well-studied proteins, the functions of many "sex-body" proteins are still uncertain. As reviewed by Handel (Handel, 2004), "sex-body" proteins, such as XMR (Escalier and Garchon, 2000), XYbp (Mazo and Pa, 2000), XY77, and ASY (Turner et al., 2000), all specifically localize in the sex 


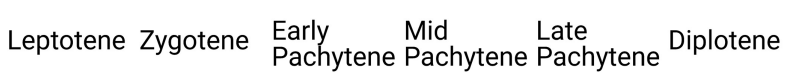

\begin{tabular}{|c|c|c|}
\hline \multirow{2}{*}{$\begin{array}{c}\text { Sex } \\
\text { chromosomes } \\
\text { behavior }\end{array}$} & \multicolumn{2}{|r|}{ Sex chromosome synapsis } \\
\hline & & Formation of sex body \\
\hline \multirow{3}{*}{$\mathrm{MSCl}$ events } & \multicolumn{2}{|r|}{ YH2AX } \\
\hline & $\begin{array}{c}\text { BRCA1 } \\
\text { (Punctate) }\end{array}$ & BRCA1(Unsynapsed region) \\
\hline & & ATR-TOPBP1, MDC1, SETDB1, TRIM28 \\
\hline $\begin{array}{l}\text { Other proteins } \\
\text { on sex } \\
\text { chromosomes }\end{array}$ & & $\begin{array}{l}\text { HP1 } \beta \text { and } \gamma, \text { SUMO-1 and its substrates, } \\
\text { SUV39H2, MacroH2A1.2, XMR, XYbp ... }\end{array}$ \\
\hline
\end{tabular}

FIGURE 3 | Schematic of sex chromosomes behavior, MSCl events, and loading of other proteins on the sex body during meiotic prophase I. Top: Sex chromosomes start to synapse at zygotene stage and keep synapsis at PAR until diplotene stage. The cytologically observed sex body forms at early pachytene and maintains until diplotene stage. Middle: Two waves of $\gamma \mathrm{H} 2 \mathrm{AX}$ are identified during meiotic prophase I. It loads onto the X chromosome as early as leptotene stage and to the $Y$ chromosome at late zygotene stage. Then, it remains on the sex chromosomes axis and spreads genome-wide during pachytene stage, and maintains until diplotene stage. BRCA1 is first found on sex chromosomes at late zygotene stage, shown as punctate staining, and then remains on the unsynapsed axis from pachytene to diplotene. DDR factors, including ATR-TOPBP1, MDC1, SETDB1, and TRIM28, appear on sex chromosomes from late zygotene stage or early pachytene stage. Bottom: Other proteins found on the sex body during pachytene to diplotene stages. Although the function of these proteins is not clear yet, it is possible they are involved in histone modifications, phase separation, and the formation of the sex body.

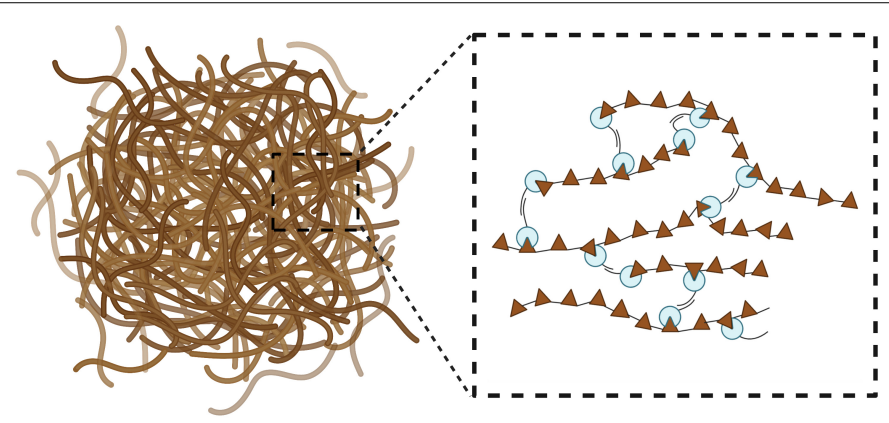

Proteins with high content of IDR in sex body: MDC1, SETDB1...

Other potential phase-separating proteins in sex body:

HP1 $\beta$ and $\gamma$, PML, DAXX

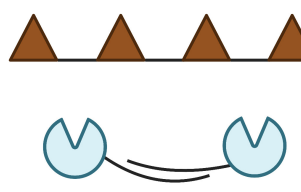

Scaffold: Protein with multivalent RNA-binding domains (RBDs), and/or IDRs, or nucleic acid with RBD recognition elements and specific secondary strucutre.

Client: Protein with multivalent RNA-binding domains and/or IDRs, or nucleic acid with multiple protein recognition sites and specific secondary structure.

FIGURE 4 | A model for multivalent interactions driving LLPS in sex body. Multivalent scaffold molecules (brown) recruit client molecules (blue) to form a phase-separated liquid droplet. Scaffolds are essential components of the phase-separated body while clients are dispensable and often present under certain conditions. Client molecules, which are not required for the condensate formation, bind to interaction domains/elements on scaffolds. Weak multivalent interactions between scaffolds and clients drive the LLPS. Potential phase-separating proteins are listed, including proteins with high content of IDR and other potential proteins.

body; whereas, the functions of these proteins remain unknown. To investigate the mechanisms of the sex-body formation, future studies should link heterochromatin formation and phase separation with transcriptional silencing and illustrate the timing of these events.

\section{INTRODUCTION TO LIQUID-LIQUID PHASE SEPARATION (LLPS)}

In the cell, LLPS is a biophysical phenomenon where macromolecules (such as proteins or nucleic acids) condense into a dense phase that demixes and creates multiple co-existing phases. LLPS has been proposed to drive the formation of many membraneless intracellular condensates and transform the way we think about subcellular organization. No membrane is observed surrounding the sex body, which leads to the idea that LLPS might separate sex chromosomes from autosomes to form the sex body. In a eukaryotic cell, intracellular space is divided into several membrane-bound organelles, each of which conducts different functions. Besides the canonical organelles bound by phospholipid bilayer membranes, many cellular compartments/condensates are not membrane-delimited, such as nucleoli, and still can separate themselves from other cellular 
components. Although these condensates are able to maintain their sizes and shapes, their assemblies are very dynamic and reversible. Environmental changes, such as composition, protein concentration, temperature, $\mathrm{pH}$, and salt concentration, could all affect LLPS. Due to its dynamics, membraneless compartments can exert vital cellular functions and respond to environmental changes. For example, stress granules (SGs) are the LLPS-promoted assemblies of proteins and mRNAs under stress stimuli. They specifically function in the response to stress (Molliex et al., 2015).

So far, the detailed mechanisms of LLPS formation remain unclear. However, previous studies suggested that intermolecular multivalent interactions, including interactions between proteins, RNA, DNA, and membrane surface, are major drives of LLPS (Pak et al., 2016). A general model of scaffolds and clients is proposed to form the biomolecular condensates (Figure 4). Scaffolds are essential for the condensate formation. Protein scaffolds recruit various clients through intrinsically disordered regions (IDRs) while RNA scaffolds recruit clients via recognition elements of the RNA binding domains (RBDs) (Ditlev et al., 2018; Espinosa et al., 2020). Several characteristics of proteins and amino acids are responsible for forming phase-separated liquid droplets (Safaee and Michnick, 2016). For example, Wang et al. (2018) revealed that the LLPS of FUS-family proteins is driven by interactions between tyrosine and arginine residues. Liquid-droplet-forming proteins often contain low-complexity domains (LCDs). LCDs are composed of only a few different types of amino acids, either repeats of individual amino acids or short amino acid motifs. In addition, multiple-folded binding domains can interact with other peptides or nucleic acids; like
LCD, proteins containing them have the ability to form phaseseparated droplets (Banjade et al., 2015). Some theories have been proposed to mediate LLPS, such as the beta-amyloid formation model (Padrick and Miranker, 2002), the multivalent domain interaction network model (Falkenberg et al., 2013), and the polymer theory (Pappu et al., 2008), which have been reviewed by previous literature (Safaee and Michnick, 2016). However, how liquid droplets are assembled in a step-by-step manner still awaits for further investigations.

Phase separation is revealed to be responsible for the formation of heterochromatin (Strom et al., 2017). Similar to the heterochromatin regions, the sex body in male spermatocytes is also formed by heterochromatinization, suggesting a similar mechanism underlying the formation and silencing of both heterochromatin regions of autosomes and the sex body. To reveal these mechanisms, the common factors involved in phase separation within the two heterochromatic regions are still to be identified.

\section{LLPS IN THE FORMATION OF NUCLEAR COMPARTMENTALIZATION}

As a common phenomenon in the cell, LLPS is found to exert a variety of functions either at a single-cell level or during the development of organisms. A growing body of evidence suggests that LLPS forms phase-separated subcellular compartments (Table 1). In the nucleus, the formation of many membraneless organelles are facilitated by LLPS, such as nucleolus, Cajal body, clastosome, perinucleolar compartment, and polycomb body.

TABLE 1 | Membraneless compartments formed by LLPS in cells.

\begin{tabular}{|c|c|c|c|c|}
\hline Compartment & Key components & Properties & Potential functions & References \\
\hline P granules* & LAF-1, MEG-3, PGL-3 & $\begin{array}{l}\text { Spherical shape, undergoing } \\
\text { fusion }\end{array}$ & $\begin{array}{l}\text { Maintenance of germ cell } \\
\text { totipotency, RNA processing, and } \\
\text { storage }\end{array}$ & Brangwynne et al., 2009; Smith et al., 2016 \\
\hline Chromatoid body* & * $\mathrm{Ddx} 4$ & $\begin{array}{l}\text { Cloud-like structure in male } \\
\text { germ cells }\end{array}$ & $\begin{array}{l}\text { piRNA-based gene silencing, RNA } \\
\text { processing and storage }\end{array}$ & Kotaja and Sassone-Corsi, 2007 \\
\hline Balbiani body* & Xvelo & $\begin{array}{l}\text { Solid-like structure in } \\
\text { early-stage oocytes }\end{array}$ & $\begin{array}{l}\text { Germline specification; protecting } \\
\text { mitochondria and other organelles }\end{array}$ & Boke et al., 2016; Lei and Spradling, 2016 \\
\hline Nucleoli & FIB-1, DAO-5 & Spherical shape, 1-4 per cell & $\begin{array}{l}\text { Transcription and processing of } \\
\text { rRNA, assembly of ribosome }\end{array}$ & Berry et al., 2015; Feric et al., 2016 \\
\hline Cajal body & Coilin, FMN & Spherical shape, 0-10 per cell & $\begin{array}{l}\text { Modification and assembly of } \\
\text { snRNA and snoRNA; trafficking of } \\
\text { snRNP and snoRNP }\end{array}$ & Sawyer et al., 2019 \\
\hline Stress granules & hnRNPA1 & $100-200 \mathrm{~nm}$ in size & $\begin{array}{l}\text { mRNA metabolism and } \\
\text { translational control, involved in the } \\
\text { pathogenesis of many diseases }\end{array}$ & Molliex et al., 2015 \\
\hline PML body & SUMO/SIM, TRF1/2 & $\begin{array}{l}\text { Spheres of } 0.1-1.0 \mu \mathrm{m} \text { in } \\
\text { diameter }\end{array}$ & $\begin{array}{l}\text { DNA damage response, DNA } \\
\text { repair, telomere homeostasis }\end{array}$ & $\begin{array}{l}\text { Lallemand-Breitenbach and de Thé, 2010; Chung } \\
\text { et al., 2011; Chang et al., } 2018\end{array}$ \\
\hline Clastosome & $19 S$ and $20 S$ proteasome & Doughnut-shaped & Protein degradation & Scherl et al., 2002 \\
\hline Polycomb body & Bmi1, Pc2, CBX2 & & $\begin{array}{l}\text { Polycomb proteins mediated gene } \\
\text { paring and silencing in Drosophila. }\end{array}$ & Vincenzo Pirrotta, 2012; Plys et al., 2019 \\
\hline P-bodies & EDC3, DDX6, LSM4, DCP2 & $8-10 \mathrm{~nm}$ in diameter & Primary piRNA processing & Luo et al., 2018 \\
\hline Centrosome & $\begin{array}{l}\text { PLK1, CDK5RAP2/Cnn and } \\
\text { Aurora-A }\end{array}$ & $\begin{array}{l}\text { Consist of two barrel-shaped } \\
\text { clusters of microtubules }\end{array}$ & $\begin{array}{l}\text { Organization of microtubules and } \\
\text { regulation of cytoskeletal structures }\end{array}$ & Mahen and Venkitaraman, 2012 \\
\hline
\end{tabular}

*Indicates specific to germ cells. 
Although the functions of some phase-separated condensates remain to be determined, the majority of them are involved in transcription, processing of rRNA, modification of snRNA, snoRNA, and other nuclear RNAs/RNPs.

Except RNA-containing condensates, LLPS participates in the formation of promyelocytic leukemia protein (PML) nuclear bodies (Boisvert et al., 2000), which are involved in multiple genome maintenance pathways (Chang et al., 2018; Corpet et al., 2020). The components of the PML nuclear bodies, SUMO1 and its substrates (PML and DAXX), are also found to accumulate in the sex body (Rogers et al., 2004).

\section{LLPS DRIVES FORMATION OF HETEROCHROMATIN}

Studies have shown that LLPS mediates the formation of distinct, multi-chromosomal, membraneless heterochromatin regions (Strom et al., 2017). Heterochromatin is characterized as a tightly packed form of DNA that enriched repetitive sequences. Trimethylated $\mathrm{H} 3 \mathrm{~K} 9$ works with $\mathrm{HP} 1$ to pack DNA. HP1 is identified as an intermediate protein that bridges chromatin to form heterochromatin. Proteins containing IDRs and low-complexity sequences often trigger LLPS; HP1 $\alpha$ has both sequences and exhibits liquid demixing in vitro and in vivo (Strom et al., 2017). This phenomenon leads to the idea that the formation of heterochromatin is driven by LLPS (Larson et al., 2017). Properties and dynamics of phaseseparated droplets are also present in the heterochromatin regions/domains, such as sensitivity to the change of hydrophobic interactions. This provides further evidence suggesting that LLPS may be involved in the formation of heterochromatin. Although we have known that transcriptional repression of heterochromatin regions is associated with phase separation, it is still unclear how genes in these regions are silenced, and whether phase separation is directly related to gene silencing.

\section{LLPS AND X-CHROMOSOME INACTIVATION}

To balance the dosage of sex-linked genes in male and female cells, one of the $\mathrm{X}$ chromosomes in female is transcriptionally silenced by X chromosome inactivation (XCI) (Robert Finestra and Gribnau, 2017). Mechanisms underlying XCI have been studied for many decades in terms of protein recruitment, chromatin modification, and chromosome organization.

At the molecular level, X-inactive specific transcript (XIST), a long non-coding RNA (lnRNA), plays key regulatory roles in the repressive epigenetic modifications of XCI. A series of Xistinteracting proteins have been identified, which are involved in the transcriptional silencing and chromosome conformational changes. In the nucleus, XIST forms a cloud-like structure and works as a macromolecular platform to recruit its interactors (Minajigi et al., 2015). Histone modifiers, such as PRC1, PRC2 (Schoeftner et al., 2006; Mira-Bontenbal and Gribnau, 2016), and aurora kinase B (AURKB) (Hall et al., 2009), are identified as Xist-interactors and establish the repressive chromatin state. Cohesin proteins, including SMC1 $\alpha, \mathrm{SMC} 3, \mathrm{RAD} 21$, WAPL, and $\mathrm{PDS} 5 \mathrm{a} / \mathrm{b}$, are also found in the Xist interactome. They are all involved in the structural reorganization of the inactive X chromosome (Xi) (Minajigi et al., 2015). CCCTC-binding factor (CTCF), a master regulator of genome architecture, also directly interacts with Xist RNA and mediates longrang chromosomal interactions (Kung et al., 2015). Due to the actions of these proteins, the $\mathrm{Xi}$ is characterized by a variety of chromatin modifications (Pinter, 2016), including histone deacetylation (Belyaev et al., 1996), demethylation at histone H3 lysines 4 and 36 (Boggs et al., 2002), trimethylation of lysine 27 in histone H3 (H3K27me3) mediated by PRC2 (Zhao et al., 2008), and monoubiquitination of lysine 119 in histone H2A (H2AK119ub1) mediated by PRC1 (de Napoles et al., 2004).

Revealed by genome capture technique, $\mathrm{Hi}-\mathrm{C}$, the active and inactive $\mathrm{X}$ chromosome show different topological conformations (Robert Finestra and Gribnau, 2017). The $\mathrm{Xi}$ chromosome is depleted of active/inactive compartments as well as topologically associating domains (TADs) (Filippova et al., 2005; Giorgetti et al., 2016; Pal et al., 2019). These chromosomal structural studies link the chromatin modifications with the chromosome organization as well as Xi transcriptional silencing, which makes the mechanism of XCI a classical example to study the epigenetic processes and gene regulation. Similarly, during meiosis in mammalian males, the $\mathrm{X}$ chromosome was found to be reorganized, isolated from all autosomes, and completely lose the compartment structure in pachytene stage (Patel et al., 2019). However, evidence showed that although both MSCI and XCI involve dramatic chromosome reorganization, the structures are distinct. For example, Xi displays two megadomains separated at the DXZ4 boundary (Giorgetti et al., 2016), which is not observed in sex chromosomes during male meiosis (Alavattam et al., 2019; Wang et al., 2019).

When comparing XCI in females and the silencing of sex chromosomes (MSCI) in males, some similarities should be aware of. First, high-throughput chromosome conformation capture (Hi-C) studies revealed TADs and compartments are lost during XCI and MSCI; the chromosomewise transcriptional silencing of the $\mathrm{X}$ chromosome is a consequence of both processes (Giorgetti et al., 2016; Patel et al., 2019). Second, chromatin modifications, such as acetylation/deacetylation, methylation/demethylation, and ubiquitination, are utilized in both inactive chromatin regions. Third, more importantly, although there is still no direct evidence suggesting the involvement of phase separation in both processes, Cerase et al. (2019) summarized pieces of evidence showing that Xist assemblies resemble phase-separated condensates in size, morphology, and composition. Additionally, some binding partners of Xist have been shown to undergo LLPS and have a strong tendency for phase separation (Cerase et al., 2019). Considering the similarities between sex body and $\mathrm{Xi}$, the involvement of LLPS in the formation of the sex body should also be considered. 


\section{ASSOCIATIONS AMONG SEX CHROMOSOMES AND NUCLEOLUS}

The inactive $\mathrm{X}$ chromosome was described as the "nucleolar satellites" by Barr and Bertram (1949), indicating the close association is present between $\mathrm{Xi}$ and nucleoli. Zhang et al. (2007) also found that $80-90 \%$ of Xi localize to the nucleolus during mid-to-late $S$ phase. This association is confirmed by the genomewide mapping of nucleolus-associated chromosomal domains (NADs) (Dillinger et al., 2017). Analysis of chromatin states of NADs demonstrated that NADs are mainly heterochromatic and lack active chromatin. The localization of Xi to the condensed perinucleolar compartment is proposed to play essential roles in establishing its epigenetic status and repressing its genes (Zhang et al., 2007; Pandya-Jones et al., 2020). Similarly, the association of sex chromosomes with nucleolus was also observed decades ago (Gates, 1939). Nucleolar masses detach from the nucleolar organization sites of their autosomal origins and migrate toward the sex body at mid pachytene stage (Tres, 2005). At late pachytene stage, a half-moon-shaped nucleolus wraps up and covers half the surface of the sex body. The thread-like granule layer of the nucleolus penetrates deeply into the chromatin part of the sex body (Solari, 1969). In situ hybridization has shown that sex chromosomes were found non-randomly distributed in the nucleus and close to the nucleolus (Weipoltshammer et al., 1996; Schöfer and Weipoltshammer, 2018). It is still unknown how the association between sex body/Xi and nucleolus forms (Handel, 2020). However, we have already known phase-separation drives the formation of the nucleolus (Lafontaine et al., 2021). If sex body and Xi share similar phase-separating properties with the nucleolus, the fusion of the phase-separated sex body/Xi and nucleolus might explain these two associations.

\section{APPROACHES AND TOOLS TO STUDY LLPS}

Considering the similarity between sex body and other phaseseparated condensates, we speculate that LLPS is the mechanism that drives the formation of the sex bodies. The results from Abe et al. (2020) suggested that the LLPS-mediated sex body functions as a sink to trap other proteins, which links this special structure with its potential functions. However, there is little research focusing on the roles of LLPS in sex-body formation. Here, we summarize several experimental approaches and tools that can be applied to study how LLPS drives sex-body formation.

It is known that only a small subset of proteins are able to undergo LLPS under specific conditions. Properties and sequences associated with these phase-separated proteins have been intensively studied. Two major types of proteins have been identified to form a network of interactions and promote LLPS. First, IDR-containing proteins are essential for phase separation. Certain polar and charged amino acids are often enriched in IDRs, including glycine $(\mathrm{G})$, serine (S), glutamine $(\mathrm{Q})$, proline $(\mathrm{P})$, glutamic acid $(\mathrm{E})$, lysine $(\mathrm{K})$, and arginine $(\mathrm{R})$. These charged amino acids enable various protein-protein and
RNA-protein interactions to promote LLPS. In particular, IDRcontaining proteins with low-complexity domains exhibit phaseseparating properties. Second, the other type of phase-separated proteins is characterized by multiple folded domains that provide multivalent interactions with other proteins. For example, the SH3 domain covalently crosslinks with PRM ligands, driving phase transition (Li et al., 2012).

In common, both types of proteins mediate LLPS by multivalent interactions. Based on this property, whether a protein is able to undergo LLPS could be predicted by its primary sequence. Numerous analysis tools can be used to look for LLPS-promoting proteins, such as UniProt, BLAST, ProParam, and CIDER. In addition, LLPS predictors are generated based on searching disordered domains or regions. For example, MobiDB (Piovesan et al., 2021), D2P2, and DisMeta are powerful tools for disorder prediction. Moreover, several phase-separation predicting software have been developed. Pi-Pi predictor, Prionlike amino acid composition (PLAAC), and ZipperDB are designed for predicting the pi-pi contacts, prion-like domains, and fibril-forming segments, respectively. Alberti et al. (2019) compared and summarized the principles of different searching methods. Utilizing these tools and databases, meiotic proteins, especially those localizing to the sex body, could be screened and analyzed to determine whether they harbor phase-separating sequences and exhibit phase-separating properties. For example, using MobiDB, we obtained the disorder content of a list of meiosis-related proteins (Table 2), which helps identify phase-separation proteins in meiosis and providing the basis for future study of detailed characteristics. Among meiotic proteins we analyzed, although most of them are present in both sex chromosomes and autosomes, a DDR protein, 53BP1, accumulates in the XY body (Ahmed et al., 2007; Gupta et al., 2013; Lu et al., 2013). 53BP1 has a high content of IDR domains and has been shown to undergo phase separation (Kilic et al., 2019). In addition, MSCI-related protein, MDC1 (Ichijima et al., 2011), also shows a high percentage of disordered domains and is possibly involved in phase separation. Further in vitro and in vivo experiments should be conducted to investigate the potential roles of these two proteins in sex-body phase separation.

A growing number of in vitro experiments have been carried out to detect LLPS and study its underlying mechanisms and functions. First, in vitro phase-separation assay has been commonly used to study LLPS proteins. Second, engineered expression vectors containing fluorescence-tagged target proteins can also be utilized to study LLPS proteins in transfected cell lines, in which phase-separating behaviors could be visualized by fluorescent signals (Quiroz et al., 2020). Third, the selfassembly of phase-separating proteins in vitro can be visualized by conjugation and co-expression with fluorescent proteins, such as GFP. Fourth, approaches, including artificial modification of protein structures, changing of environmental conditions, and adding LLPS disruptors, have been used to study the dynamic features of LLPS proteins. For instance, 1,6-hexanediol, a disruptor of LLPS, is typically applied to determine whether LLPS plays a role in the formation of condensates both in vivo and in vitro (Ahn et al., 2020). Small molecules, such as kinases and ATPs, can also be added into in vitro phase-separation systems 
TABLE 2 | IDR content information of meiosis-related proteins based on MobiDB.

\begin{tabular}{|c|c|c|}
\hline Protein name & IDR content & Functions \\
\hline Testis-specific $\mathrm{H} 1$ histone $(\mathrm{H} 1 \mathrm{t})$ & 0.714 & $\begin{array}{l}\text { Associated with repressed chromatin domains in pachytene spermatocytes } \\
\text { (Mahadevan et al., 2020) }\end{array}$ \\
\hline Mediator of DNA damage checkpoint protein 1 (MDC1) & 0.697 & Functions in chromosome-wide silencing of the sex body (Ichijima et al., 2011) \\
\hline TP53-binding protein 1 (53BP1) & 0.624 & DDR protein and localizes to the sex body (Lu et al., 2013) \\
\hline Histone-lysine N-methyltransferase SETDB1 & 0.338 & Links meiotic DDR to sex chromosome silencing (Hirota et al., 2018) \\
\hline Pachytene checkpoint protein 2 homolog (Trip13) & 0.338 & $\begin{array}{l}\text { Required for recombination and meiotic chromosome structure (Roig et al., } \\
\text { 2010) }\end{array}$ \\
\hline Synaptonemal complex protein 3 (SYCP3) & 0.256 & Component of synaptonemal complex (Syrjänen et al., 2014) \\
\hline Cohesin subunit SA-3 (STAG3) & 0.173 & $\begin{array}{l}\text { Maintaining centromere chromatid cohesion; required for DSB repair and } \\
\text { synapsis (Hopkins et al., 2014) }\end{array}$ \\
\hline DNA mismatch repair protein Mlh1 & 0.146 & Homologous recombination and DSB repair (Cannavo et al., 2020) \\
\hline Synaptonemal complex protein 2 (SYCP2) & 0.144 & Component of synaptonemal complex (Feng et al., 2017) \\
\hline Serine/threonine-protein kinase Chk1 & 0.137 & DNA damage response (Nie et al., 2017) \\
\hline Meiotic recombination protein REC8 & 0.124 & Sister-chromatid cohesion and crossover recombination (Yoon et al., 2016) \\
\hline HORMA domain-containing protein 1 (HORMAD1) & 0.094 & $\begin{array}{l}\text { Synaptonemal complex formation, recombination and chromosome } \\
\text { segregation (Shin et al., 2010) }\end{array}$ \\
\hline Double-strand-break repair protein rad21-like protein 1 (Rad21L1) & 0.038 & Maintaining the integrity of meiotic chromatin architecture (Blokhina et al., 2020) \\
\hline Synaptonemal complex protein 1 (SYCP1) & 0.036 & Component of synaptonemal complex (de Vries et al., 2005) \\
\hline Serine-protein kinase ATM & 0.026 & $\begin{array}{l}\text { Controlling DSB formation and recombination (Lange et al., 2011; Kurzbauer } \\
\text { et al., 2021) }\end{array}$ \\
\hline
\end{tabular}

and exert specific biological functions (Mackenzie et al., 2017). In addition, fluorescence recovery after photobleaching (FRAP), fluorescence correlation spectroscopy (FCS), and fluorescence resonance energy transfer (FRET), are also frequently conducted to evaluate the properties of LLPS condensates.

Not only in vitro LLPS systems build our knowledge on the behavior of LLPS proteins, but in vivo studies also provided insights into LLPS droplets in cells. Endogenous phase behavior has been revealed by engineered phase-separation sensors. In the study of keratohyalin granules (KGs) in the mammalian skin barrier, modified variants of phase-separating intrinsically disordered proteins (IDPs) were fused to fluorescent proteins and acted as phase separation sensors after transducing them into mouse embryos (Quiroz et al., 2020). These IDPs do not exhibit phase-separation behavior on their own; in contrast, when exposed to phase-separated droplets, they are able to engage in phase-separation-specific interactions and report nascent phaseseparating activities. As a novel method to investigate phase separation in vivo, the phase-separation sensor can potentially be applied to explore LLPS in other tissues or cells. Additionally, mutations that alter the phase-separating properties, such as protein multivalency, can also be introduced to examine the LLPS functions (Nott et al., 2015). For instance, the hnRNP protein, TIA1, contains a C-terminal LCD domain that is predicted to be intrinsically disordered. Three ALS-associated TIA1 mutations exhibit increased phase-separation tendency that is caused by stronger protein-protein interactions (Mackenzie et al., 2017).

Although LLPS is likely a mechanism to explain the sex-body formation, other models for assembling chromatin subcompartments should also be considered as reviewed by Erdel and Rippe (2018). First, the multivalent interactions between chromatin-associated proteins promote LLPS. In polymerpolymer phase separation (PPPS) model, bridges between nucleosomes, rather than multivalent interactions in LLPS, facilitate the formation of phase-separated subcompartments within polymers (Singh and Newman, 2020). The bridging factors crosslinked chromatin fibers are usually chromatinassociated proteins lacking multivalent interactions, such as condensin (Ganji et al., 2018), cohesin (Rao et al., 2017), and YY1 (Weintraub et al., 2017). Second, without phase-separation, the simple binding between soluble factors and the chromatin scaffold is also able to form the chromatin subcompartments (Wachsmuth et al., 2008).

Experimental strategies to distinguish different mechanisms were also proposed by Erdel and Rippe (2018). First, tracking the (dis)assembly process over time could distinguish LLPS and PPPS because PPPS formation but not LLPS need nucleation sites. Thus, introducing and subsequently removing artificial nucleation sites can help us test whether LLPS multivalent interactions can hold the sex body together without nucleation sites. Second, with a concentration increase of constituting protein factors in the nucleoplasm, the size of the sex body should increase via LLPS but not via PPPS. Third, bridging factors need chromatin scaffolds to form biomolecule condensates. However, multivalent binders in LLPS can independently form condensates without chromatin scaffolds.

Some membraneless organelles can also transit from liquids (young) to gel/solid-like state (old) or have solid-like substructures, such as centrosomes (Woodruff et al., 2017). After they mature, the hardened solid-like organelles reduce the dynamics of their molecules (Banani et al., 2017), e.g., some HP1 proteins become immobile during the maturation of the heterochromatin regions/domains (Strom et al., 2017). Similarly, sex bodies might also display different material properties from liquids to solid-like feature with "aging." FRAP analysis can help us test this hypothesis (Boke et al., 2016) and show the "aged" sex 
Inactive chromatin state

Chromatin modifications

Chromosome reorganization

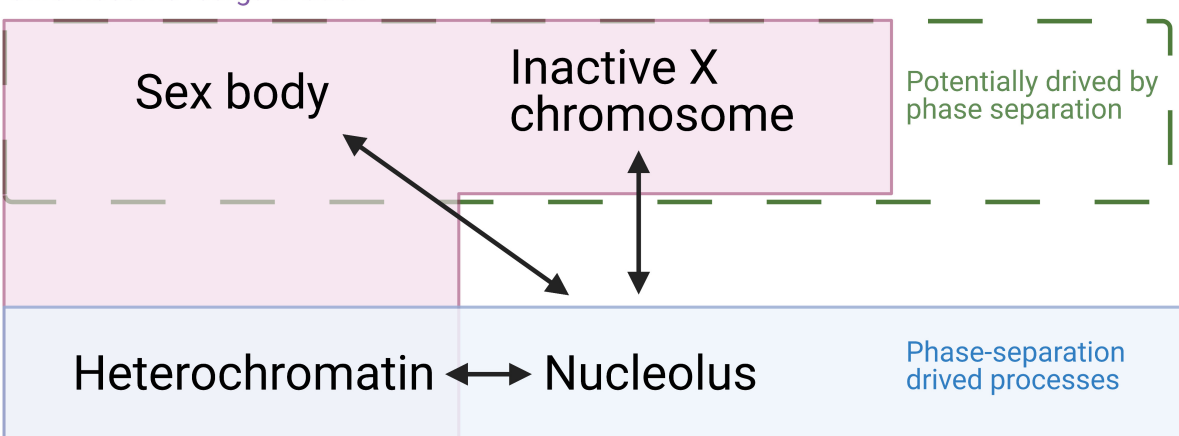

$\longleftrightarrow$ Physically associate

FIGURE 5 | A summary of similarities and associations among sex body, inactive X chromosome (Barr body), heterochromatin, and nucleolus. Sex body, Barr body, and heterochromatin are all physically associated with the nucleolus. While heterochromatin and nucleolus are confirmed to be driven by phase separation, sex body and Barr body are hypothesized to be formed by LLPS. In addition, sex body, Barr body, and heterochromatin all present inactive chromatin state, dramatic chromatin modifications, chromosome reorganizations. These similarities and associations raise the possibility that sex body is formed by LLPS.

body may not recover after full or partial bleaching. If it is true, the solid-like "aged" sex body loses its ability to incorporate and internally rearrange the fluorescence-tagged target proteins. This will be consistent with the idea that the hardened mature sex body serves as a sink to sequester its trapped proteins, including the DDR proteins, from the rest of the pachytene nucleoplasm (Abe et al., 2020).

\section{CONCLUDING REMARKS AND FUTURE DIRECTIONS}

Liquid-liquid phase separation is a driver for the assembly of membraneless biomolecular condensates in cells. It exerts a variety of functions, including sequestration of molecules, buffering molecule concentration, regulating the specificity and kinetics of biochemical reactions, genomic organization, RNA processing, and generating meiotic DNA breaks (Banani et al., 2017; Claeys Bouuaert et al., 2021). During male meiosis, sex chromosomes are reorganized, transcriptionally silenced by MSCI, and form a visibly distinct membraneless structure at pachytene stage. Although the molecular basis of MSCI has been extensively studied, it is not yet known what factors drive the formation of the sex body and mediate gene repression.

Here, we summarized several points that suggest there are similarities between the sex body and other phaseseparation condensates and gene silencing processes (Figure 5). Firstly, the sex body has a similar appearance to other membraneless droplets formed by phase-separation and a separate territory that has a low interaction frequency with autosomes. Secondly, heterochromatin, which is structurally reorganized and transcriptionally silenced, is known to be formed by LLPS. Similarly, sex bodies also share the silencing status and histone modification with heterochromatin regions, such as H3K9me3. Thirdly, the phase-separating protein HP1 drives the formation of heterochromatin. Two isoforms of HP1, HP1 $\beta$, and $\mathrm{HP} 1 \gamma$, also localize to the sex body in spermatocytes (MetzlerGuillemain et al., 2003), indicating the resemblance of sex body and heterochromatin. Fourthly, MSCI also resembles XCI in female somatic cells. Both processes involve the recruitment of a set of proteins, histone modifications, chromosome reorganization, and transcriptional silencing. Cerase et al. (2019) gathered evidence and proposed a hypothesis that phase separation drives XCI. Overall, the similarities between sex-body formation and phase-separating processes raise the possibility that LLPS is a common driving force underlying all these processes-formation of the sex body, heterochromatin, and inactivation of the $\mathrm{X}$ chromosome.

Ever-growing experimental methods have been developed to study characteristics and mechanisms of LLPS, including both in vivo and in vitro approaches. Although growing clues indicate LLPS drives sex-body formation, so far, there is still no direct proof. In the future, approaches investigating LLPS in other cellular bodies could be applied to analyze sex-body formation. Softwares and tools analyzing protein sequences and phase-separating domains can be used to identify sex-body proteins involved in phase separation. Any identified phaseseparating proteins can be further studied by in vitro or in vivo experiments. Established methods for visualizing the behavior of liquid condensates formed by LLPS will shed a light on the phase-separating process of sex bodies. Disrupting chemicals, such as 1,6-hexanediol, can be added to protein aggregates to determine whether phase separation will be disturbed. Phase separation sensors will enable the inspection of LLPS activity in vivo. Understanding the driving force and factors involved in sex-body formation is still challenging, however, new ways to explore LLPS characteristics will expand our knowledge on the properties of the sex bodies. By applying these methods to study proteins in the sex body, future studies are likely to identify many phase-separating proteins in the sex body. It is also intriguing to 
know how some X-linked genes can escape MSCI in these phaseseparated sex bodies. We speculate those gene regions may locate at the phase boundary/the surface of the sex body and dissociate from phase-separating components. A challenge in the future is to understand how these "sex body" proteins drive the sex-body formation step-by-step and how the structure of the sex body is maintained until the diplotene stage in spermatocytes.

\section{AUTHOR CONTRIBUTIONS}

YX and HQ contributed to the writing and editing of this review. Both authors contributed to the article and approved the submitted version.

\section{REFERENCES}

Abe, H., Alavattam, K. G., Hu, Y., Pang, Q., Andreassen, P. R., Hegde, R. S., et al. (2020). The initiation of meiotic sex chromosome inactivation sequesters DNA damage signaling from autosomes in mouse spermatogenesis. Curr. Biol. 30, 408-420. doi: 10.1016/j.cub.2019.11.064

Ahmed, E. A., van der Vaart, A., Barten, A., Kal, H. B., Chen, J., Lou, Z., et al. (2007). Differences in DNA double strand breaks repair in male germ cell types: lessons learned from a differential expression of $\mathrm{Mdc1}$ and 53BP1. DNA Repair (Amst) 6, 1243-1254. doi: 10.1016/j.dnarep.2007.02.011

Ahn, J. I., Park, J. E., Meng, L., Zhang, L., Kim, T. S., Kruhlak, M. J., et al. (2020). Phase separation of the Cep63•Cep152 complex underlies the formation of dynamic supramolecular self-assemblies at human centrosomes. Cell Cycle 19, 3437-3457. doi: 10.1080/15384101.2020.1843777

Alavattam, K. G., Maezawa, S., Sakashita, A., Khoury, H., Barski, A., Kaplan, N., et al. (2019). Attenuated chromatin compartmentalization in meiosis and its maturation in sperm development. Nat. Struct. Mol. Biol. 26, 175-184. doi: 10.1038/s41594-019-0189-y

Alberti, S., Gladfelter, A., and Mittag, T. (2019). Considerations and challenges in studying liquid-liquid phase separation and biomolecular condensates. Cell 176, 419-434. doi: 10.1016/j.cell.2018.12.035

Aumiller, W. M., Davis, B. W., and Keating, C. D. (2014). Phase separation as a possible means of nuclear compartmentalization. Int. Rev. Cell Mol. Biol. 307, 109-149. doi: 10.1016/b978-0-12-800046-5.00005-9

Baarends, W. M., Wassenaar, E., van der Laan, R., Hoogerbrugge, J., SleddensLinkels, E., Hoeijmakers, J. H. J., et al. (2005). Silencing of unpaired chromatin and histone H2A ubiquitination in mammalian meiosis. Mol. Cell. Biol. 25, 1041-1053. doi: 10.1128/MCB.25.3.1041-1053.2005

Banani, S. F., Lee, H. O., Hyman, A. A., and Rosen, M. K. (2017). Biomolecular condensates: organizers of cellular biochemistry. Nat. Rev. Mol. Cell Biol. 18, 285-298. doi: 10.1038/nrm.2017.7

Banjade, S., Wu, Q., Mittal, A., Peeples, W. B., Pappu, R. V., and Rosen, M. K. (2015). Conserved interdomain linker promotes phase separation of the multivalent adaptor protein Nck. Proc. Natl. Acad. Sci. U S A. 112, E6426E6435. doi: 10.1073/pnas.1508778112

Barr, M. L., and Bertram, E. G. (1949). A morphological distinction between neurones of the male and female, and the behaviour of the nucleolar satellite during accelerated nucleoprotein synthesis. Nature 163, 676-677. doi: 10.1038/ $163676 \mathrm{a} 0$

Belyaev, N. D., Keohane, A. M., and Turner, B. M. (1996). Differential underacetylation of histones $\mathrm{H} 2 \mathrm{~A}, \mathrm{H} 3$ and $\mathrm{H} 4$ on the inactive $\mathrm{X}$ chromosome in human female cells. Hum. Genet. 97, 573-578. doi: 10.1007/BF02281863

Berry, J., Weber, S. C., Vaidya, N., Haataja, M., Brangwynne, C. P., and Weitz, D. A. (2015). RNA transcription modulates phase transition-driven nuclear body assembly. Proc. Natl. Acad. Sci. U S A. 112, E5237-E5245. doi: 10.1073/ pnas. 1509317112

Biggs, R. J., Liu, N., Peng, Y., Marko, J. F., and Qiao, H. (2020). Micromanipulation of prophase I chromosomes from mouse spermatocytes reveals high stiffness

\section{FUNDING}

This work was supported by NIH R00 HD082375 and NIH R01 GM135549.

\section{ACKNOWLEDGMENTS}

We would like to thank Dr. Satoshi Namekawa for his comments on this manuscript. We apologize to colleagues whose work may not have been cited due to length limitations. We thank Ning Liu, Yiheng Peng, Royal Shrestha, Aashna Prakash, Faaiza Nusayba Saif, and Erica Hana Joo for critical proofreading of the manuscript. We want to thank Yiheng Peng for helping to generate Figure 1.

and gel-like chromatin organization. Commun. Biol. 3:542. doi: 10.1038/ s42003-020-01265-w

Blokhina, Y. P., Frees, M., Nguyen, A., Sharifi, M., Chu, D. B., Draper, B. W., et al. (2020). Rad2111 cohesin subunit is dispensable for spermatogenesis but not oogenesis in zebrafish. bioRxiv [preprint] doi: 10.1101/2020.09.23.309591

Boggs, B. A., Cheung, P., Heard, E., Spector, D. L., Chinault, A. C., and Allis, C. D. (2002). Differentially methylated forms of histone $\mathrm{H} 3$ show unique association patterns with inactive human X chromosomes. Nat. Genet. 30, 73-76. doi: $10.1038 / \mathrm{ng} 787$

Boisvert, F. M., Hendzel, M. J., and Bazett-Jones, D. P. (2000). Promyelocytic leukemia (PML) nuclear bodies are protein structures that do not accumulate RNA. J. Cell Biol. 148, 283-292. doi: 10.1083/jcb.148.2.283

Boke, E., Ruer, M., Wühr, M., Coughlin, M., Lemaitre, R., Gygi, S. P., et al. (2016). Amyloid-like self-assembly of a cellular compartment. Cell 166, 637-650. doi: 10.1016/j.cell.2016.06.051

Brangwynne, C. P., Eckmann, C. R., Courson, D. S., Rybarska, A., Hoege, C., Gharakhani, J., et al. (2009). Germline P granules are liquid droplets that localize by controlled dissolution/condensation. Science 324, 1729-1732. doi: 10.1126/ science. 1172046

Burgoyne, P. S. (1982). Genetic homology and crossing over in the X and Y chromosomes of mammals. Hum. Genet. 61, 85-90. doi: 10.1007/BF00274192

Cannavo, E., Sanchez, A., Anand, R., Ranjha, L., Hugener, J., Adam, C., et al. (2020). Regulation of the MLH1-MLH3 endonuclease in meiosis. Nature 586, 618-622. doi: 10.1038/s41586-020-2592-2592

Cerase, A., Armaos, A., Neumayer, C., Avner, P., Guttman, M., and Tartaglia, G. G. (2019). Phase separation drives X-chromosome inactivation: a hypothesis. Nat. Struct. Mol. Biol. 26, 331-334. doi: 10.1038/s41594-019-0223-220

Chang, H. R., Munkhjargal, A., Kim, M. J., Park, S. Y., Jung, E., Ryu, J. H., et al. (2018). The functional roles of PML nuclear bodies in genome maintenance. Mutat. Res. - Fundam. Mol. Mech. Mutagen. 809, 99-107. doi: 10.1016/j. mrfmmm.2017.05.002

Chen, Y., Zheng, Y., Gao, Y., Lin, Z., Yang, S., Wang, T., et al. (2018). Singlecell RNA-seq uncovers dynamic processes and critical regulators in mouse spermatogenesis. Cell Res. 28, 879-896. doi: 10.1038/s41422-018-0074-y

Chung, I., Leonhardt, H., and Rippe, K. (2011). De novo assembly of a PML nuclear subcompartment occurs through multiple pathways and induces telomere elongation. J. Cell Sci. 124, 3603-3618. doi: 10.1242/jcs.084681

Claeys Bouuaert, C., Pu, S., Wang, J., Oger, C., Daccache, D., Xie, W., et al. (2021). DNA-driven condensation assembles the meiotic DNA break machinery. Nature 592, 144-149. doi: 10.1038/s41586-021-03374-w

Corpet, A., Kleijwegt, C., Roubille, S., Juillard, F., Jacquet, K., Texier, P., et al. (2020). PML nuclear bodies and chromatin dynamics: catch me if you can! Nucleic Acids Res. 48, 11890-11912. doi: 10.1093/nar/gkaa828

Daniel, K., Lange, J., Hached, K., Fu, J., Anastassiadis, K., Roig, I., et al. (2011). Meiotic homologous chromosome alignment and its surveillance are controlled by mouse HORMAD1. Nat. Cell Biol. 13, 599-610. doi: 10.1038/ncb2213

de Napoles, M., Mermoud, J. E., Wakao, R., Tang, Y. A., Endoh, M., Appanah, R., et al. (2004). Polycomb group proteins ring1A/B link ubiquitylation of 
histone H2A to heritable gene silencing and X inactivation. Dev. Cell 7, 663-676. doi: 10.1016/j.devcel.2004.10.005

de Vries, F. A. T., de Boer, E., van den Bosch, M., Baarends, W. M., Ooms, M., Yuan, L., et al. (2005). Mouse Sycp1 functions in synaptonemal complex assembly, meiotic recombination, and XY body formation. Genes Dev. 19, 1376-1389. doi: $10.1101 /$ gad. 329705

Dillinger, S., Straub, T., and Németh, A. (2017). Nucleolus association of chromosomal domains is largely maintained in cellular senescence despite massive nuclear reorganisation. PLoS One 12:e0178821. doi: 10.1371/journal. pone. 0178821

Ditlev, J. A., Case, L. B., and Rosen, M. K. (2018). Who's in and who's outcompositional control of biomolecular condensates. J. Mol. Biol. 430, 46664684. doi: 10.1016/j.jmb.2018.08.003

Erdel, F., and Rippe, K. (2018). Formation of chromatin subcompartments by phase separation. Biophys. J. 114, 2262-2270. doi: 10.1016/j.bpj.2018.03.011

Escalier, D., and Garchon, H. (2000). XMR is associated with the asynapsed segments of sex chromosomes in the XY body of mouse primary spermatocytes. Chromosoma 109, 259-265. doi: 10.1007/s004120000075

Espinosa, J. R., Joseph, J. A., Sanchez-Burgos, I., Garaizar, A., Frenkel, D., and Collepardo-Guevara, R. (2020). Liquid network connectivity regulates the stability and composition of biomolecular condensates with many components. Proc. Natl. Acad. Sci. U S A. 117, 13238-13247. doi: 10.1073/pnas.1917569117

Falkenberg, C. V., Blinov, M. L., and Loew, L. M. (2013). Pleomorphic ensembles: formation of large clusters composed of weakly interacting multivalent molecules. Biophys. J. 105, 2451-2460. doi: 10.1016/j.bpj.2013.10.016

Feng, J., Fu, S., Cao, X., Wu, H., Lu, J., Zeng, M., et al. (2017). Synaptonemal complex protein 2 (SYCP2) mediates the association of the centromere with the synaptonemal complex. Protein Cell 8, 538-543. doi: 10.1007/s13238-0160354-356

Feric, M., Vaidya, N., Harmon, T. S., Mitrea, D. M., Zhu, L., Richardson, T. M., et al. (2016). Coexisting liquid phases underlie nucleolar subcompartments. Cell 165, 1686-1697. doi: 10.1016/j.cell.2016.04.047

Fernandez-capetillo, O., Mahadevaiah, S. K., Celeste, A., Romanienko, P. J., Camerini-otero, R. D., Bonner, W. M., et al. (2003). H2AX is required for chromatin remodeling and inactivation of sex chromosomes in male mouse meiosis. Dev. Cell 4, 497-508. doi: 10.1016/s1534-5807(03)00093-5

Filippova, G. N., Cheng, M. K., Moore, J. M., Truong, J. P., Hu, Y. J., Nguyen, D. K., et al. (2005). Boundaries between chromosomal domains of $\mathrm{X}$ inactivation and escape bind CTCF and lack CpG methylation during early development. Dev. Cell 8, 31-42. doi: 10.1016/j.devcel.2004.10.018

Ganji, M., Shaltiel, I. A., Bisht, S., Kim, E., Kalichava, A., Haering, C. H., et al. (2018). Real-time imaging of DNA loop extrusion by condensin. Science 360, 102-105. doi: 10.1126/science.aar7831

Gates, R. R. (1939). Nucleoli, satellites and sex chromosomes. Nature 144, 794-795. doi: 10.1038/144794a0

Giorgetti, L., Lajoie, B. R., Carter, A. C., Attia, M., Zhan, Y., Xu, J., et al. (2016). Structural organization of the inactive X chromosome in the mouse. Nature 535, 575-579. doi: 10.1038/nature 18589

Goetz, P., Chandley, A. C., and Speed, R. M. (1984). Morphological and temporal sequence of meiotic prophase development at puberty in the male mouse. J. Cell Sci. 65, 249-263. doi: 10.1242/jcs.65.1.249

Green, C. D., Ma, Q., Manske, G. L., Shami, A. N., Zheng, X., Marini, S., et al. (2018). A comprehensive roadmap of murine spermatogenesis defined by single-Cell RNA-Seq. Dev. Cell 46, 651-667.e10. doi: 10.1016/j.devcel.2018. 07.025

Gupta, A., Hunt, C. R., Chakraborty, S., Pandita, R. K., Yordy, J., Ramnarain, D. B., et al. (2013). Role of 53BP1 in the regulation of DNA double-strand break repair pathway choice. Radiat. Res. 181, 1-8. doi: 10.1667/RR13572.1

Hall, L. L., Byron, M., Pageau, G., and Lawrence, J. B. (2009). AURKB-mediated effects on chromatin regulate binding versus release of XIST RNA to the inactive chromosome. J. Cell Biol. 186, 491-507. doi: 10.1083/jcb.200811143

Handel, M. A. (2004). The XY body: a specialized meiotic chromatin domain. Exp. Cell Res. 296, 57-63. doi: 10.1016/j.yexcr.2004.03.008

Handel, M. A. (2020). The XY body: an attractive chromatin domain. Biol. Reprod. 102, 985-987. doi: 10.1093/biolre/ioaa021

Hirota, T., Blakeley, P., Sangrithi, M. N., Mahadevaiah, S. K., Encheva, V., Snijders, A. P., et al. (2018). SETDB1 links the meiotic DNA damage response to sex chromosome silencing in mice. Dev. Cell 47, 645-659.e6. doi: 10.1016/j.devcel. 2018.10.004

Hnisz, D., Shrinivas, K., Young, R. A., Chakraborty, A. K., and Sharp, P. A. (2017). A phase separation model for transcriptional control. Cell 169, 13-23. doi: $10.1016 /$ j.cell.2017.02.007

Hopkins, J., Hwang, G., Jacob, J., Sapp, N., Bedigian, R., Oka, K., et al. (2014). Meiosis-specific cohesin component, Stag3 is essential for maintaining centromere chromatid cohesion, and required for DNA repair and synapsis between homologous chromosomes. PLoS Genet. 10:e1004413. doi: 10.1371/ journal.pgen.1004413

Ichijima, Y., Ichijima, M., Lou, Z., Nussenzweig, A., Daniel Camerini-Otero, R., Chen, J., et al. (2011). MDC1 directs chromosome-wide silencing of the sex chromosomes in male germ cells. Genes Dev. 25, 959-971. doi: 10.1101/gad. 2030811

Ichijima, Y., Sin, H. S., and Namekawa, S. H. (2012). Sex chromosome inactivation in germ cells: emerging roles of DNA damage response pathways. Cell. Mol. Life Sci. 69, 2559-2572. doi: 10.1007/s00018-012-0941-945

Jung, M., Wells, D., Rusch, J., Ahmad, S., Marchini, J., Myers, S. R., et al. (2019). Unified single-cell analysis of testis gene regulation and pathology in five mouse strains. eLife 8:e43966. doi: 10.7554/elife.43966

Kaplan, W. D., Kinosita, R., and Ohno, S. (1956). Concentration of RNA on the heteropycnotic XY bivalent of the rat. Exp. Cell Res. 11, 520-526. doi: 10.1016/ 0014-4827(56)90161-90166

Ke, Y., Xu, Y., Chen, X., Feng, S., Liu, Z., Sun, Y., et al. (2017). 3D chromatin structures of mature gametes and structural reprogramming during mammalian embryogenesis. Cell 170, 367-381.e20. doi: 10.1016/j.cell.2017. 06.029

Khalil, A. M., Boyar, F. Z., and Driscoll, D. J. (2004). Dynamic histone modifications mark sex chromosome inactivation and reactivation during mammalian spermatogenesis. Proc. Natl. Acad. Sci. U S A. 101, 16583-16587. doi: 10.1073/pnas.0406325101

Kilic, S., Lezaja, A., Gatti, M., Bianco, E., Michelena, J., Imhof, R., et al. (2019). Phase separation of 53BP1 determines liquid-like behavior of DNA repair compartments. EMBO J. 38:e101379. doi: 10.15252/embj.2018101379

Kotaja, N., and Sassone-Corsi, P. (2007). The chromatoid body: a germ-cellspecific RNA-processing centre. Nat. Rev. Mol. Cell Biol. 8, 85-90. doi: 10.1038/ nrm2081

Kung, J. T., Kesner, B., Erwin, J. A., and Lee, J. T. (2015). Locus-Specific targeting to the X chromosome revealed by the RNA interactome of CTCF. Mol. Cell 57 , 361-375. doi: 10.1016/j.molcel.2014.12.006

Kurzbauer, M.-T., Janisiw, M. P., Paulin, L. F., Prusén Mota, I., Tomanov, K., Krsicka, O., et al. (2021). ATM controls meiotic DNA double-strand break formation and recombination and affects synaptonemal complex organization in plants. Plant Cell 33, 1633-1656. doi: 10.1093/plcell/koab045

Lafontaine, D. L. J., Riback, J. A., Bascetin, R., and Brangwynne, C. P. (2021). The nucleolus as a multiphase liquid condensate. Nat. Rev. Mol. Cell Biol. 22, 165-182. doi: 10.1038/s41580-020-0272-276

Lallemand-Breitenbach, V., and de Thé, H. (2010). PML nuclear bodies. Cold Spring Harb. Perspect. Biol. 2:a000661. doi: 10.1101/cshperspect.a0 00661

Lange, J., Pan, J., Cole, F., Thelen, M. P., Jasin, M., and Keeney, S. (2011). ATM controls meiotic double-strand-break formation. Nature 479, 237-240. doi: 10.1038 /nature 10508

Larson, A. G., Elnatan, D., Keenen, M. M., Trnka, M. J., Johnston, J. B., Burlingame, A. L., et al. (2017). Liquid droplet formation by HP1 $\alpha$ suggests a role for phase separation in heterochromatin. Nat. Publ. Gr. 547, 236-240. doi: 10.1038/ nature 22822

Lau, X., Munusamy, P., Ng, M. J., and Sangrithi, M. (2020). Single-Cell RNA sequencing of the cynomolgus macaque testis reveals conserved transcriptional profiles during mammalian spermatogenesis. Dev. Cell 54, 548-566.e7. doi: 10.1016/J.DEVCEL.2020.07.018

Lei, L., and Spradling, A. C. (2016). Mouse oocytes differentiate through organelle enrichment from sister cyst germ cells. Science 352, 95-99. doi: 10.1126/science. aad2156

Li, P., Banjade, S., Cheng, H. C., Kim, S., Chen, B., Guo, L., et al. (2012). Phase transitions in the assembly of multivalent signalling proteins. Nature 483 , 336-340. doi: 10.1038/nature10879 
Lu, L.-Y., Xiong, Y., Kuang, H., Korakavi, G., and Yu, X. (2013). Regulation of the DNA damage response on male meiotic sex chromosomes. Nat. Commun. 4:2105. doi: $10.1038 /$ ncomms 3105

Lukassen, S., Bosch, E., Ekici, A. B., and Winterpacht, A. (2018). Single-cell RNA sequencing of adult mouse testes. Sci. Data 5:180192. doi: 10.1038/sdata.20 18.192

Luo, Y., Na, Z., and Slavoff, S. A. (2018). P-Bodies: composition, properties, and functions. Biochemistry 57, 2424-2431. doi: 10.1021/acs.biochem.7b01162

Mackenzie, I. R., Nicholson, A. M., Sarkar, M., Messing, J., Purice, M. D., Pottier, C., et al. (2017). TIA1 mutations in amyotrophic lateral sclerosis and frontotemporal dementia promote phase separation and alter stress granule dynamics. Neuron 95, 808-816. doi: 10.1016/j.neuron.2017.07.025

Mahadevan, I. A., Kumar, S., and Rao, M. R. S. (2020). Linker histone variant $\mathrm{H} 1 \mathrm{t}$ is closely associated with repressed repeat-element chromatin domains in pachytene spermatocytes. Epigenetics Chromatin 13:9. doi: 10.1186/s13072020-00335- $x$

Mahen, R., and Venkitaraman, A. R. (2012). Spatial patterning of P granules by RNA-induced phase separation of the intrinsically-disordered protein MEG-3. Curr. Opin. Cell Biol. 24, 14-23. doi: 10.1016/j.ceb.2011.12.012

Mazo, Â, and Pa, M. (2000). XYbp, a novel RING-finger protein, is a component of the XY body of spermatocytes and centrosomes. Mech. Dev. 90, 95-101. doi: 10.1016/s0925-4773(99)00223-3

Metzler-Guillemain, C., Luciani, J., Depetris, D., Guichaoua, M. R., and Mattei, M. G. (2003). HP1 $\beta$ and HP1 $\gamma$, but not HP1 $\alpha$, decorate the entire XY body during human male meiosis. Chromosom. Res. 11, 73-81. doi: 10.1023/A: 1022014217196

Minajigi, A., Froberg, J. E., Wei, C., Sunwoo, H., Kesner, B., Colognori, D., et al. (2015). A comprehensive Xist interactome reveals cohesin repulsion and an RNA-directed chromosome conformation. Science 349:aab2276. doi: 10.1126/ science.aab2276

Mira-Bontenbal, H., and Gribnau, J. (2016). New xist-interacting proteins in X-Chromosome inactivation. Curr. Biol. 26, R338-R342. doi: 10.1016/j.cub. 2016.03.022

Molliex, A., Temirov, J., Lee, J., Coughlin, M., Kanagaraj, A. P., Kim, H. J., et al. (2015). Phase separation by low complexity domains promotes stress granule assembly and drives pathological fibrillization. Cell 163, 123-133. doi: 10.1016/ j.cell.2015.09.015

Namekawa, S. H. (2012). Sex chromosome inactivation in germ cells: emerging roles of DNA damage response pathways. Cell Mol. Life Sci. 69, 2559-2572. doi: 10.1007/s00018-012-0941-5

Nie, Z.-W., Chen, L., Jin, Q.-S., Gao, Y.-Y., Wang, T., Zhang, X., et al. (2017). Function and regulation mechanism of Chk1 during meiotic maturation in porcine oocytes. Cell Cycle 16, 2220-2229. doi: 10.1080/15384101.2017. 1373221

Nott, T. J., Petsalaki, E., Farber, P., Jervis, D., Fussner, E., Plochowietz, A., et al. (2015). Phase transition of a disordered nuage protein generates environmentally responsive membraneless organelles. Mol. Cell 57, 936-947. doi: 10.1016/j.molcel.2015.01.013

O'Carroll, D., Scherthan, H., Peters, A. H. F. M., Opravil, S., Haynes, A. R., Laible, G., et al. (2000). Isolation and characterization ofSuv39h2, a second histone H3 methyltransferase gene that displays testis-specific expression. Mol. Cell. Biol. 20, 9423-9433. doi: 10.1128/mcb.20.24.9423-9433.2000

Padrick, S. B., and Miranker, A. D. (2002). Islet amyloid: phase partitioning and secondary nucleation are central to the mechanism of fibrillogenesis. Biochemistry 41, 4694-4703. doi: 10.1021/bi0160462

Page, J., de la Fuente, R., Manterola, M., Parra, M. T., Viera, A., Berríos, S., et al. (2012). Inactivation or non-reactivation: what accounts better for the silence of sex chromosomes during mammalian male meiosis? Chromosoma 121, 307-326. doi: 10.1007/s00412-012-0364-y

Pak, C. W., Kosno, M., Holehouse, A. S., Padrick, S. B., Mittal, A., Ali, R., et al. (2016). Sequence determinants of intracellular phase separation by complex coacervation of a disordered protein. Mol. Cell 63, 72-85. doi: 10.1016/j.molcel. 2016.05.042

Pal, K., Forcato, M., Jost, D., Sexton, T., Vaillant, C., Salviato, E., et al. (2019). Global chromatin conformation differences in the Drosophila dosage compensated chromosome X. Nat. Commun. 10:5355. doi: 10.1038/s41467-019-1335013358
Pandya-Jones, A., Markaki, Y., Serizay, J., Chitiashvili, T., Mancia Leon, W. R., Damianov, A., et al. (2020). A protein assembly mediates Xist localization and gene silencing. Nature 587, 145-151. doi: 10.1038/s41586-020-2703-2700

Pappu, R. V., Wang, X., Vitalis, A., and Crick, S. L. (2008). A polymer physics perspective on driving forces and mechanisms for protein aggregation. Arch. Biochem. Biophys. 469, 132-141. doi: 10.1016/j.abb.2007.08.033

Patel, L., Kang, R., Rosenberg, S. C., Qiu, Y., Raviram, R., Chee, S., et al. (2019). Dynamic reorganization of the genome shapes the recombination landscape in meiotic prophase. Nat. Struct. Mol. Biol. 26, 164-174. doi: 10.1038/s41594-0190187-180

Peng, A., and Weber, S. C. (2019). Evidence for and against liquid-liquid phase separation in the nucleus. Non-coding RNA 5:50. doi: 10.3390/ncrna5040050

Perry, J., Palmer, S., Gabriel, A., and Ashworth, A. (2001). A short pseudoautosomal region in laboratory mice. Genome Res. 11, 1826-1832. doi: 10.1101/gr.203001

Pinter, S. F. (2016). A tale of two cities: how xist and its partners localize to and silence the bicompartmental X. Semin. Cell Dev. Biol. 56, 19-34. doi: 10.1016/j. semcdb.2016.03.023

Piovesan, D., Necci, M., Escobedo, N., Monzon, A. M., Hatos, A., Mičetić, I., et al. (2021). MobiDB: intrinsically disordered proteins in 2021. Nucleic Acids Res. 49, D361-D367. doi: 10.1093/nar/gkaa1058

Plys, A. J., Davis, C. P., Kim, J., Rizki, G., Keenen, M. M., Marr, S. K., et al. (2019). Phase separation of polycomb-repressive complex 1 is governed by a charged disordered region of CBX2. Genes Dev. 33, 799-813. doi: 10.1101/gad.3264 88.119

Quiroz, F. G., Fiore, V. F., Levorse, J., Polak, L., Wong, E., Pasolli, H. A., et al. (2020). Liquid-liquid phase separation drives skin barrier formation. Science 367:eaax9554. doi: 10.1126/science.aax9554

Rao, S. S. P., Huang, S. C., Glenn, St Hilaire, B., Engreitz, J. M., Perez, E. M., et al. (2017). Cohesin loss eliminates all loop domains. Cell 171, 305-320.e24. doi: 10.1016/j.cell.2017.09.026

Razin, S. V., and Gavrilov, A. A. (2020). The role of liquid-liquid phase separation in the compartmentalization of cell nucleus and spatial genome organization. Biochemistry 85, 643-650. doi: 10.1134/S0006297920060012

Reuben, M., and Lin, R. (2002). Germline X chromosomes exhibit contrasting patterns of histone H3 methylation in Caenorhabditis elegans. Dev. Biol. 245, 71-82. doi: 10.1006/dbio.2002.0634

Robert Finestra, T., and Gribnau, J. (2017). X chromosome inactivation: silencing, topology and reactivation. Curr. Opin. Cell Biol. 46, 54-61. doi: 10.1016/j.ceb. 2017.01.007

Rogers, R. S., Inselman, A., Handel, M. A., and Matunis, M. J. (2004). SUMO modified proteins localize to the XY body of pachytene spermatocytes. Chromosoma 113, 233-243. doi: 10.1007/s00412-004-0311-317

Roig, I., Dowdle, J. A., Toth, A., de Rooij, D. G., Jasin, M., and Keeney, S. (2010). Mouse TRIP13/PCH2 is required for recombination and normal higher-order chromosome structure during meiosis. PLoS Genet. 6:e1001062. doi: 10.1371/ journal.pgen.1001062

Royo, H., Polikiewicz, G., Mahadevaiah, S. K., Prosser, H., Mitchell, M., Bradley, A., et al. (2010). Evidence that meiotic sex chromosome inactivation is essential for male fertility. Curr. Biol. 20, 2117-2123. doi: 10.1016/j.cub.2010.11.010

Royo, H., Prosser, H., Ruzankina, Y., Mahadevaiah, S., Cloutier, J., Baumann, M., et al. (2013). ATR acts stage specifically to regulate multiple aspects of mammalian meiotic silencing. Genes Dev. 27, 1484-1494. doi: 10.1101/gad. 219477.113

Royo, H., Seitz, H., ElInati, E., Peters, A. H. F. M., Stadler, M. B., and Turner, J. M. A. (2015). Silencing of X-Linked MicroRNAs by meiotic sex chromosome inactivation. PLoS Genet. 11:e1005461. doi: 10.1371/journal.pgen.1005461

Safaee, N., and Michnick, S. W. (2016). Mechanisms and consequences of macromolecular phase separation. Cell 165, 1067-1079. doi: 10.1016/j.cell.2016. 05.026

Sawyer, I. A., Sturgill, D., and Dundr, M. (2019). Membraneless nuclear organelles and the search for phases within phases. Wiley Interdiscip. Rev. RNA 10:e1514. doi: 10.1002/wrna.1514

Scherl, A., Coute, Y., De, C., Calle, A., Sanchez, J., Greco, A., et al. (2002). Clastosome: a subtype of nuclear body enriched in $19 \mathrm{~S}$ and $20 \mathrm{~S}$ proteasomes. Mol. Biol. Cell 13, 4100-4109. doi: 10.1091/mbc.E02

Schoeftner, S., Sengupta, A. K., Kubicek, S., Mechtler, K., Spahn, L., Koseki, H., et al. (2006). Recruitment of PRC1 function at the initiation of X inactivation 
independent of PRC2 and silencing. EMBO J. 25, 3110-3122. doi: 10.1038/sj. emboj.7601187

Schöfer, C., and Weipoltshammer, K. (2018). Nucleolus and chromatin. Histochem. Cell Biol. 150, 209-225. doi: 10.1007/s00418-018-1696-1693

Shin, Y.-H., Choi, Y., Erdin, S. U., Yatsenko, S. A., Kloc, M., Yang, F., et al. (2010). Hormad1 mutation disrupts synaptonemal complex formation, recombination, and chromosome segregation in mammalian meiosis. PLoS Genet. 6:e1001190. doi: 10.1371/journal.pgen.1001190

Singh, P. B., and Newman, A. G. (2020). On the relations of phase separation and Hi-C maps to epigenetics. R. Soc. Open Sci. 7:191976. doi: 10.1098/rsos.191976

Smith, J., Calidas, D., Schmidt, H., Lu, T., Rasoloson, D., and Seydoux, G. (2016). Spatial patterning of $\mathrm{P}$ granules by RNA-induced phase separation of the intrinsically-disordered protein MEG-3. eLife 5: e21337. doi: 10.7554/eLife. 21337

Solari, A. J. (1969). The evolution of the ultrastructure of the sex chromosomes (sex vesicle) during meiotic prophase in mouse spermatocytes. J. Ultrastruct. Res. 27, 289-305. doi: 10.1016/S0022-5320(69)80018-80013

Solari, A. J. (1974). The behavior of the XY pair in mammals. Int Rev Cytol. 38, 273-317. doi: 10.1016/s0074-7696(08)60928-6

Solari, A. J., and Tres, L. (1967). The localization of nucleic acids and the argentaffin substance in the sex vesicle of mouse spermatocytes. Exp. Cell Res. 47, 86-96. doi: 10.1016/0014-4827(67)90212-90211

Strom, A. R., Emelyanov, A., Mir, M., Fyodorov, D., Darzacq, X., and Carpen, G. (2017). Phase separation drives heterochromatin domain formation. Nat. Publ. Gr. 547, 241-245. doi: 10.1038/nature22989

Syrjänen, J. L., Pellegrini, L., and Davies, O. R. (2014). A molecular model for the role of SYCP3 in meiotic chromosome organisation. eLife 3:e02963. doi: $10.7554 /$ eLife.02963

Tres, L. L. (2005). XY chromosomal bivalent: nucleolar attraction. Mol. Reprod. Dev. 72, 1-6. doi: 10.1002/mrd.20334

Turner, J. M. A. (2015). Meiotic silencing in mammals. Annu. Rev. Genet. 49, 395-412. doi: 10.1146/annurev-genet-112414-155145

Turner, J. M. A., Aprelikova, O., Xu, X., Wang, R., Kim, S., Chandramouli, G. V. R., et al. (2004). BRCA1, histone H2AX phosphorylation, and male meiotic sex chromosome inactivation. Curr. Biol. 14, 2135-2142. doi: 10.1016/j.cub.2004. 11.032

Turner, J. M. A., Mahadevaiah, S. K., Benavente, R., Offenberg, H. H., Heyting, C., and Burgoyne, P. S. (2000). Analysis of male meiotic "sex body" proteins during $\mathrm{XY}$ female meiosis provides new insights into their functions. Chromosoma 109, 426-432. doi: 10.1007/s004120000097

Turner, J. M. A., Mahadevaiah, S. K., Fernandez-Capetillo, O., Nussenzweig, A., Xu, X., Deng, C. X., et al. (2005). Silencing of unsynapsed meiotic chromosomes in the mouse. Nat. Genet. 37, 41-47. doi: 10.1038/ng1484

van der Heijden, G. W., Derijck, A. A. H. A., Pósfai, E., Giele, M., Pelczar, P., Ramos, L., et al. (2007). Chromosome-wide nucleosome replacement and H3.3 incorporation during mammalian meiotic sex chromosome inactivation. Nat. Genet. 39, 251-258. doi: 10.1038/ng1949

Vara, C., Paytuví-Gallart, A., Cuartero, Y., Le Dily, F., Garcia, F., Salvà-Castro, J., et al. (2019). Three-Dimensional genomic structure and cohesin occupancy correlate with transcriptional activity during spermatogenesis. Cell Rep. 28, 352-367.e9. doi: 10.1016/j.celrep.2019.06.037

Vincenzo Pirrotta, H.-B. L. (2012). A view of nuclear Polycomb bodies. Curr. Opin. Genet. Dev. 22, 101-109. doi: 10.1016/j.gde.2011.11.004.A
Wachsmuth, M., Caudron-Herger, M., and Rippe, K. (2008). Genome organization: balancing stability and plasticity. Biochim. Biophys. Acta - Mol. Cell Res. 1783, 2061-2079. doi: 10.1016/j.bbamcr.2008.07.022

Wang, J., Choi, J. M., Holehouse, A. S., Lee, H. O., Zhang, X., Jahnel, M., et al. (2018). A molecular grammar governing the driving forces for phase separation of prion-like RNA binding proteins. Cell 174, 688-699.e16. doi: 10.1016/j.cell. 2018.06.006

Wang, Y., Wang, H., Zhang, Y., Du, Z., Si, W., Fan, S., et al. (2019). Reprogramming of meiotic chromatin architecture during spermatogenesis. Mol. Cell 73, 547561.e6. doi: 10.1016/j.molcel.2018.11.019

Weintraub, A. S., Li, C. H., Zamudio, A. V., Sigova, A. A., Hannett, N. M., Day, D. S., et al. (2017). YY1 is a structural regulator of enhancer-promoter loops. Cell 171, 1573-1588.e28. doi: 10.1016/j.cell.2017. 11.008

Weipoltshammer, K., Schöfer, C., Almeder, M., Sylvester, J., and Wachtler, F. (1996). Spatial distribution of sex chromosomes and ribosomal genes: a study on human lymphocytes and testicular cells. Cytogenet. Genome Res. 73, 108113. doi: $10.1159 / 000134319$

Wojtasz, L., Cloutier, J. M., Baumann, M., Daniel, K., Varga, J., Fu, J., et al. (2012). Meiotic DNA double-strand breaks and chromosome asynapsis in mice are monitored by distinct HORMAD2-independent and -dependent mechanisms. Genes Dev. 26, 958-973. doi: 10.1101/gad.187559.112

Woodruff, J. B., Ferreira Gomes, B., Widlund, P. O., Mahamid, J., Honigmann, A., and Hyman, A. A. (2017). The centrosome is a selective condensate that nucleates microtubules by concentrating tubulin. Cell 169, 1066-1077.e10. doi: 10.1016/j.cell.2017.05.028

Yoon, S.-W., Lee, M.-S., Xaver, M., Zhang, L., Hong, S.-G., Kong, Y.-J., et al. (2016). Meiotic prophase roles of Rec8 in crossover recombination and chromosome structure. Nucleic Acids Res. 44, 9296-9314. doi: 10.1093/nar/g kw682

Zhang, L.-F., Huynh, K. D., and Lee, J. T. (2007). Perinucleolar Targeting of the Inactive $\mathrm{X}$ during $\mathrm{S}$ Phase: evidence for a role in the maintenance of silencing. Cell 129, 693-706. doi: 10.1016/j.cell.2007.03.036

Zhao, J., Sun, B. K., Erwin, J. A., Song, J.-J., and Lee, J. T. (2008). Polycomb proteins targeted by a short repeat RNA to the mouse X chromosome. Science 322, 750-756. doi: 10.1126/science. 1163045

Conflict of Interest: The authors declare that the research was conducted in the absence of any commercial or financial relationships that could be construed as a potential conflict of interest.

Publisher's Note: All claims expressed in this article are solely those of the authors and do not necessarily represent those of their affiliated organizations, or those of the publisher, the editors and the reviewers. Any product that may be evaluated in this article, or claim that may be made by its manufacturer, is not guaranteed or endorsed by the publisher.

Copyright (C) $2021 \mathrm{Xu}$ and Qiao. This is an open-access article distributed under the terms of the Creative Commons Attribution License (CC BY). The use, distribution or reproduction in other forums is permitted, provided the original author(s) and the copyright owner(s) are credited and that the original publication in this journal is cited, in accordance with accepted academic practice. No use, distribution or reproduction is permitted which does not comply with these terms. 